\title{
Updating Finite Element Model of a Wind Turbine Blade Section Using Experimental Modal Analysis Results
}

\author{
Marcin Luczak, ${ }^{1}$ Simone Manzato, ${ }^{2}$ Bart Peeters, ${ }^{2}$ Kim Branner, ${ }^{3}$ \\ Peter Berring, ${ }^{3}$ and Maciej Kahsin ${ }^{4}$ \\ ${ }^{1}$ Institute of Fluid-Flow Machinery Polish Academy of Sciences, Gdansk, Poland \\ ${ }^{2}$ LMS International, Leuven, Belgium \\ ${ }^{3}$ Department of Wind Energy, Technical University of Denmark, Denmark \\ ${ }^{4}$ Gdansk University of Technology, Gdansk, Poland
}

Correspondence should be addressed to Simone Manzato; simone.manzato@lmsintl.com

Received 3 March 2014; Accepted 3 March 2014; Published 15 July 2014

Academic Editor: Miguel M. Neves

Copyright (C) 2014 Marcin Luczak et al. This is an open access article distributed under the Creative Commons Attribution License, which permits unrestricted use, distribution, and reproduction in any medium, provided the original work is properly cited.

\begin{abstract}
This paper presents selected results and aspects of the multidisciplinary and interdisciplinary research oriented for the experimental and numerical study of the structural dynamics of a bend-twist coupled full scale section of a wind turbine blade structure. The main goal of the conducted research is to validate finite element model of the modified wind turbine blade section mounted in the flexible support structure accordingly to the experimental results. Bend-twist coupling was implemented by adding angled unidirectional layers on the suction and pressure side of the blade. Dynamic test and simulations were performed on a section of a full scale wind turbine blade provided by Vestas Wind Systems A/S. The numerical results are compared to the experimental measurements and the discrepancies are assessed by natural frequency difference and modal assurance criterion. Based on sensitivity analysis, set of model parameters was selected for the model updating process. Design of experiment and response surface method was implemented to find values of model parameters yielding results closest to the experimental. The updated finite element model is producing results more consistent with the measurement outcomes.
\end{abstract}

\section{Introduction}

Wind turbine blades must be designed to resist the extreme load cases and fatigue loads from normal operation. Sudden wind gusts are often too quick for the active pitch control system to react and may shorten the fatigue life substantially. This problem may be overcome by an aeroelastic tailoring of the blades. Particular implementation of the anisotropic composite material can introduce the bend-twist coupling in the blade [1-4]. In [5] a new beam element, which is able to take the behavior of anisotropic materials into account, is developed and implemented into the aeroelastic code HAWC2. This makes it possible to simulate wind turbines with structural couplings in the blades. The coupling causes the feathering blade to twist under the bending load and as a result decreases the angle of attack. The original wind turbine blade section made of composite material was statically tested and modeled with model validation analysis $[6,7]$. Based on the analysis outcomes the bendtwist coupling design of existing blade was modified by means of additional composite material layers. In [8] an overview of the statistical and modal analysis experiments on the original and modified blade section is presented. In this paper the updating of the modified wind turbine blade section's finite element model using experimental modal analysis is presented. Finite element (FE) model updating has become an important tool used in structural dynamics $[9,10]$. A number of FE model updating procedures have been proposed [11-13]. Direct, noniterative methods update the FE model properties in one-step procedure [14]. The methods based on sensitivity of the parameters solve the optimization problem in an iterative procedure. Examples of application of static strain measurements for FE model updating are noted [15]. Multiobjective optimization technique applied 


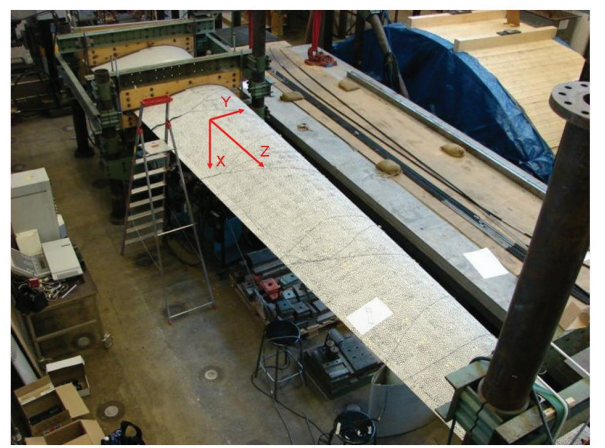

FIGURE 1: Experimental set-up showing the wind turbine blade section mounted on the test rig with the coordinate system.

TABLE 1: Basic information about geometry and material properties used for modeling of supporting structure.

\begin{tabular}{lcccc}
\hline Geometry $[\mathrm{mm}]$ & Pipes & C-Shapes & I-Shapes & Plywood \\
& Inner radius 170 Outer radius 160 & Standard UPN 200 & Two bolted standard UPN 200 & Thickness 180 \\
\hline E modulus $[\mathrm{GPa}]$ & 200 & 200 & 200 & 13.2 \\
Density $\left[\mathrm{kg} / \mathrm{m}^{3}\right]$ & 7890 & 7890 & 7890 & 736 \\
Poisson's Ratio & 0.3 & 0.3 & 0.3 & 0.01 \\
\hline
\end{tabular}

to update the FE models of civil engineering structures in structural dynamics is reported [16-18]. Iterative updating using sensitivity based methods requires large number of computations of FE models with modified parameter values $[9,19,20]$. Response surface method (RSM) based meta-model is an approximation of the FE model which could be replaced in the updating procedure [21, 22]. RSM method is widely used in engineering applications $[19,23$, 24]. Sections 2 and 3 of this paper present the structural dynamics identification, which was performed by means of experimental modal analysis. The RSM based FE model updating procedure using design of experiment (DOE) to estimate the structural parameters based on measured natural frequencies and mode shapes is presented in Section 4. The FE model was updated and validated against experimentally identified dynamic behavior of the modified blade section with support structure. The influence of the support structure dynamics on the test specimen is discussed.

\section{Object of the Investigations}

The object of investigation is an 8-meter long section cut from a 23-meter wind turbine blade. Blade section is mounted in the two root clamps (Figure 1).

The blade is a hollow structure with two shells. The two shells form the suction and pressure side of the blade. To join the two shells together the structural web is incorporated. Investigated blade designed by Vestas has a load carrying box girder. The original blade section was modified with four layers of UD1200, which were laminated on the pressure and suction side of the blade with the fibers angle of $25^{\circ}$ to create a measurable flapwise bend-twist coupling. The additional layers were laminated as indicated in $[6,7]$. Support structure is built with use of cylindrical beams (steel pipes), "I" and "C" shaped UNP-profiles, and airfoil contour-cut plywood clamps. Geometry and material properties are presented in Table 1 .

\section{Experimental and Numerical Investigation of Structural Dynamics of Modified Blade Section}

The modified blade section was investigated by means of experimental modal analysis. Particular focus was on the influence of the support structure in the correlation analysis between numerical and experimental modal models $[25,26]$.

3.1. Experimental Campaign and Results. Blade section was excited with two electrodynamic shakers attached at the tip end in the flapwise and edgewise directions. Frequency response functions were measured and stored within 0 and $120 \mathrm{~Hz}$ frequency range.

For adequate identification of the blade dynamic displacement, accelerations of the vibrations were measured in 130 points. Thirteen equidistant measurement cross-sections were defined along the span-wise direction $(Z)$ every 0.5 (m). Each cross-section contains five measurement points in which accelerations were acquired along the flapwise $(X)$ and edgewise $(Y)$ direction. These points are located at the leading edge, trailing edge, on the line of airfoil maximum thickness, and in the midpoints between the previous three. Measurement directions were precisely defined based on the CAD geometry of the blade section.

Model quality assessment was an integrated part of the investigation. Except time invariance another condition must be observed to satisfy of modal analysis assumptions: linearity, Maxwell's reciprocity principle, and observability. Possible sources of nonlinearities within investigated structure are material properties, geometrical properties, and the existence 
of bond connections verification of a superposition rule is one of the methods of detecting nonlinearities. Linearity check was done for the level of driving voltage ranging from 0.5 $(\mathrm{V})$ to $2(\mathrm{~V})$ with a step of $0.5(\mathrm{~V})$. Results are presented in Figure 2. Frequency response function (FRF) between input signal and output spectrum defined as acceleration over force remains constant independently of excitation voltage level. This proves that the structure dynamic behavior is linear within bandwidth of interest.

The reciprocity check is based on Maxwell's principle, which states that the FRFs obtained by applying the force on point 1 and measuring the response in 2 and vice versa should be the same. The results for the two checks performed confirmed applicability of the reciprocity rule.

During the processing of the data, some significant noise was observed in the acquired FRFs in the low frequency region. The driving point coherence functions show a small drop in this region, meaning a nonideal excitation (Figure 3 ).

The modal parameter identification technique was not able to clearly stabilize modes in this region, possibly resulting in some local errors in the mode shapes below $7 \mathrm{~Hz}$. The estimation provided natural frequencies, mode shapes, and corresponding damping ratios in the frequency bandwidth 0 $60 \mathrm{~Hz}$. First five out of 12 identified mode shapes are provided in Figure 4. MAC (modal assurance criterion) can be used to compare two modal models [27]. If a linear relationship exists between the two complex vectors, the MAC value will be near to 1 . If they are linearly independent, the MAC value will be small (near zero). Figure 5 shows a comparison between the AutoMAC of the modal model obtained by considering only the sensors on the blade and the one where also the response of the supporting structure is included.

Low valued off-diagonal terms for the blade only model ensure linear independence of estimated modal vectors. The correlation between off-diagonal terms is increased when including the supporting structure in the analysis. This is due to the fact that the clamping is not perfectly rigid and the support has its own dynamic behavior which influences the measured response of the blade.

In Figure 5, red color corresponds to MAC value equal 100. Light green color reflects the MAC value 0 . Modes corresponding to frequencies $8 \mathrm{~Hz}, 28 \mathrm{~Hz}, 31 \mathrm{~Hz}$, and $33 \mathrm{~Hz}$ are related to dynamic properties of the supporting structure. Additionally, appraisal of (a) and (c) in Figure 5 shows that the numerical model basing solely on blade geometry yields less distinctive mode shapes. Comparing Figures 5(a) and $5(\mathrm{c})$, the correlation of the off-main diagonal terms of the AutoMAC is lower which is a desired situation due to distinction of mode shapes. The model producing undistinguished mode shapes is not suitable for model updating.

\subsection{FE Model of the Blade Section with Support Structure.} The numerical model adopts MSC.Patran/Nastran blade FE model (Figure 6). It is comprised of 8-noded shell elements (Quad8) and the 20-noded solid elements (Hex20). This model has approximately 600000 degrees of freedom [6]. The original FE model of the blade was developed to study the static response. The blade section was fully fixed at the chosen

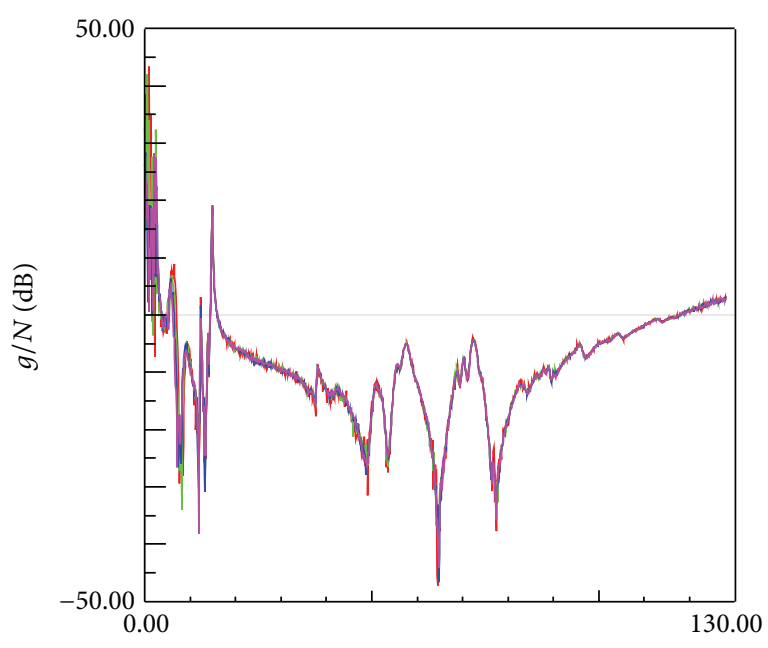

$(\mathrm{Hz})$

口 F—— FRF Drvp:1:+Y/Drvp:1:+Y linearity_check_05 V

口 F— FRF Drvp:1:+Y/Drvp:1:+Y linearity_check_10 V

口 F- FRF Drvp:1:+Y/Drvp:1:+Y linearity_check_15 V

口 F_— FRF Drvp:1:+Y/Drvp:1:+Y linearity_check_20 V

FIgURE 2: Linearity check for one of the points on the blade. Voltage values $=0.5 \mathrm{~V}, 1 \mathrm{~V}, 1,5 \mathrm{~V}$, and $2 \mathrm{~V}$.

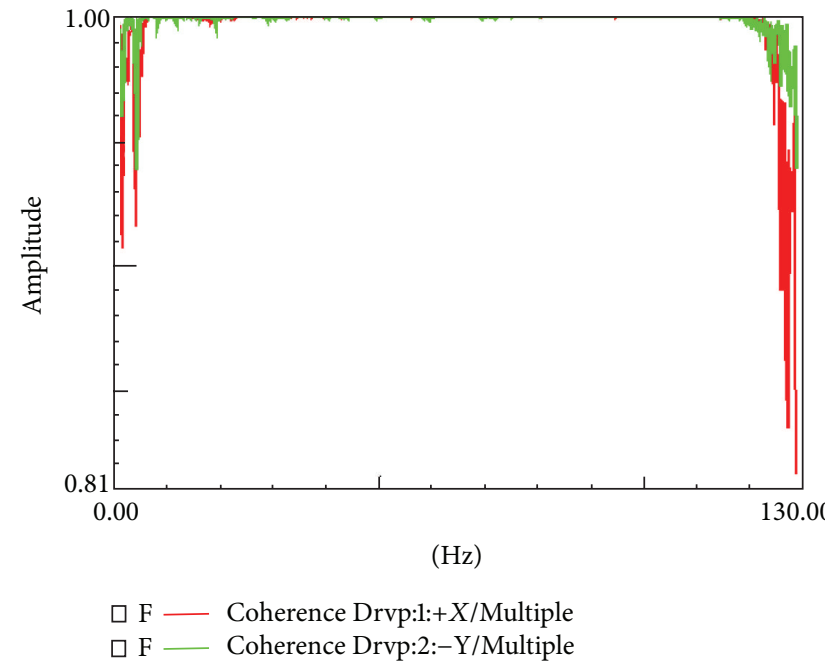

FIGURE 3: Coherence functions for the two driving points. It is used as measure of the FRF quality. Ideally it should take value equal to 1 .

cross-section near the boundary to represent the clamped configuration of the test rig.

The boundary conditions which were adequately representing support structure in static analysis $[6,7,28]$ were used in the initial theoretical modal analysis. In the correlation analysis of the test and FE modal models it turned out that a nonnegligible discrepancy in mode shapes occurs. Relatively light and flexible support (Figure 5(b)) has significant contribution on the mode shapes of studied structure which can be observed in the MAC values (Figure 5(c)). In order to eliminate abovementioned problem, an additional support structure model had to be introduced into the blade 


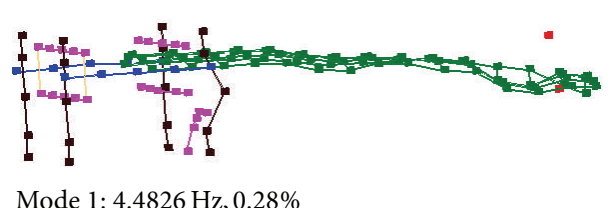

Mode 1: $4.4826 \mathrm{~Hz}, 0.28 \%$

$$
\underset{\substack{Y \\ X}}{Y} Z
$$

(a) 1st bend flap, $\omega=4.48 \mathrm{~Hz}$

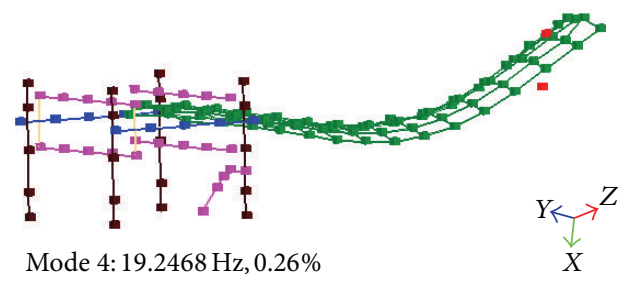

(c) 2nd bend flap, $\omega=19.24 \mathrm{~Hz}$

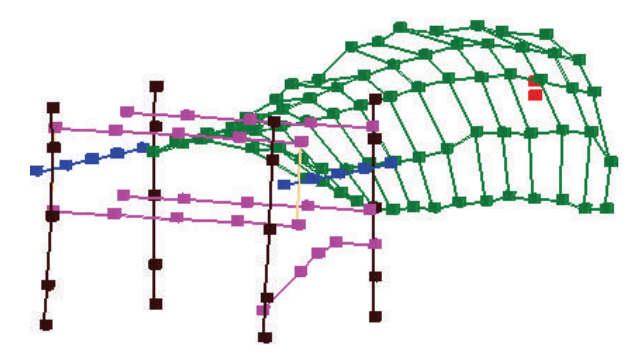

Mode 8: $40.9234 \mathrm{~Hz}, 0.63 \%$

$$
\underset{\mathrm{X}}{\stackrel{\mathrm{X}}{\mathrm{Z}}}
$$

(e) 1st torsion, $\omega=40.92 \mathrm{~Hz}$

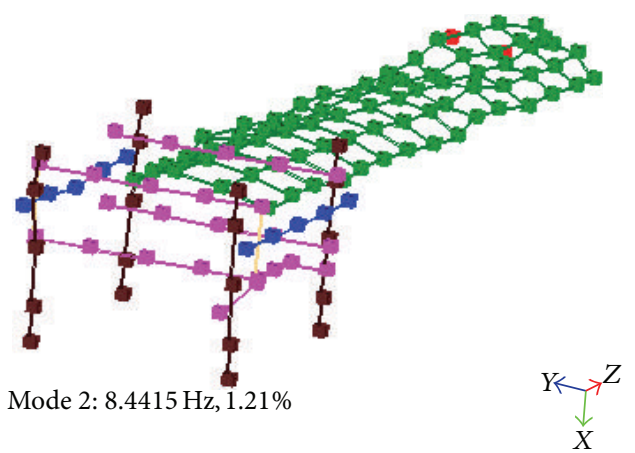

(b) 1st bend edge, $\omega=8.44 \mathrm{~Hz}$

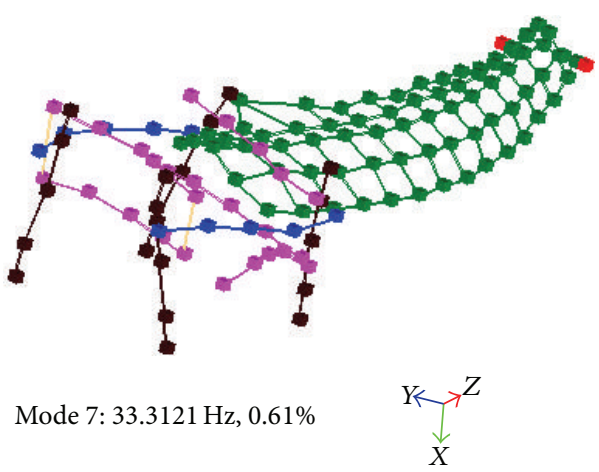

(d) 2 nd bend edge, $\omega=33.31 \mathrm{~Hz}$

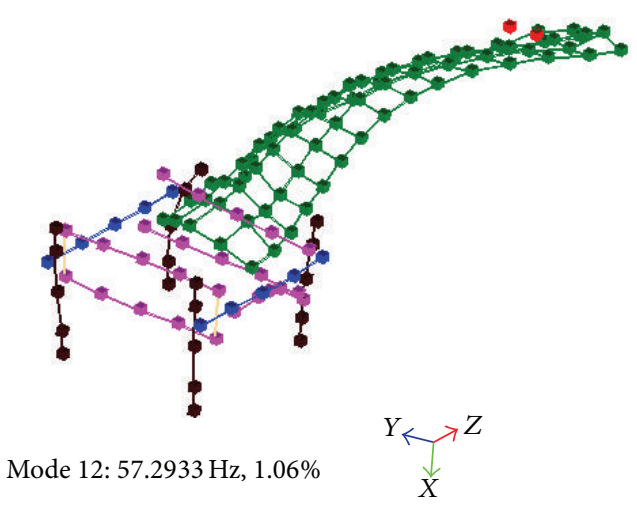

(f) Bend-torsion, $\omega=57.29 \mathrm{~Hz}$

FIGURE 4: Estimated experimental mode shapes of the modified blade section and support structure.

section test set-up FE model. The main assumption prior modification of original FE model was to keep additional FE model as simple as possible, due to the fact that numerical model was yet relatively large, while making it possible to correlate simulation results with measured data in all points used in the test phase.

As it can be seen in Figure 6 left, the real supporting structure comprises of pipes, UNP-profiles, and support clams of contour-cut plywood. Basic information about geometry and material properties exploited in derived additional FE model are presented in Table 1 .

The additional FE model consists of beam elements (CBEAM in Nastran notation), shell elements representing plywood (QUAD8), elastic springs representing mountings between beam elements (CELAS1), rigid bars connecting plywood and I shape clamp beams (RBE2 and), and additional rigid bars with ends at position corresponding to the position of measuring points from test setup (RBAR). Rigid connection between plywood and I shapes is justified because of the large difference in E modules of both materials. Representation of FE-to-test matching with rigid bars does not introduce additional stiffness to the system and is acceptable as long as global mode shapes of support are of interest only. After preparation of support FE model, both additional and the original FE models were merged. Nodes at the interface between blade and supporting structure, that is, between plywood and outer surface of the blade, have restrained rotational DOFs. Such an approach was taken because in the 


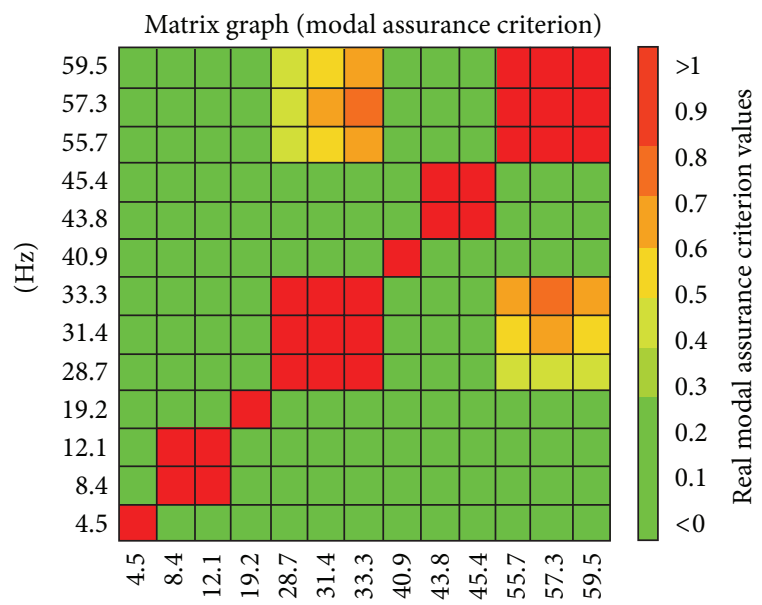

$(\mathrm{Hz})$

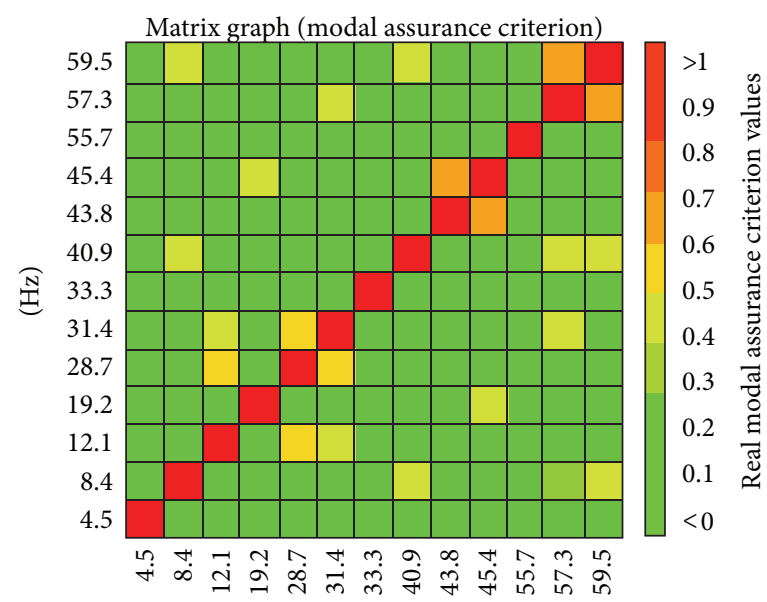

$(\mathrm{Hz})$

(a) AutoMac blade only

(b) AutoMac support only

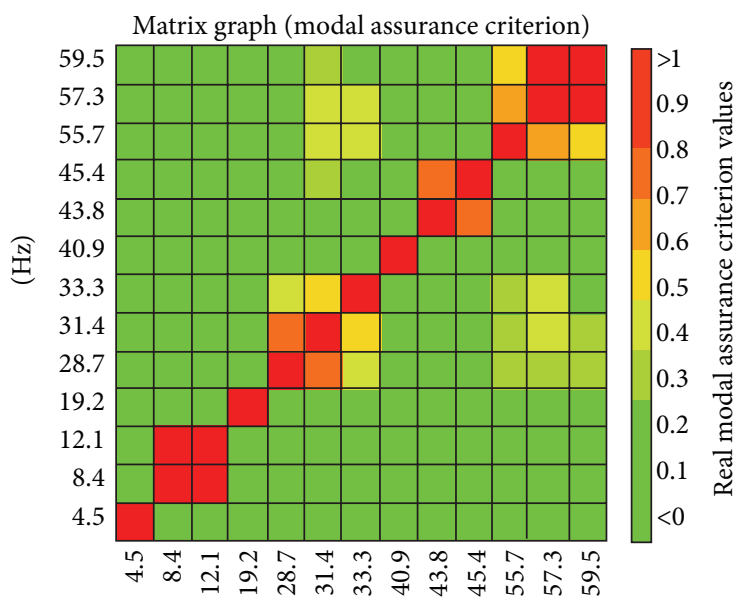

$(\mathrm{Hz})$

(c) AutoMac complete structure

FIGURE 5: AutoMAC matrices for experimental modal models with sensors only on the modified blade section (a), support structure (b), and blade section with support structure (c).

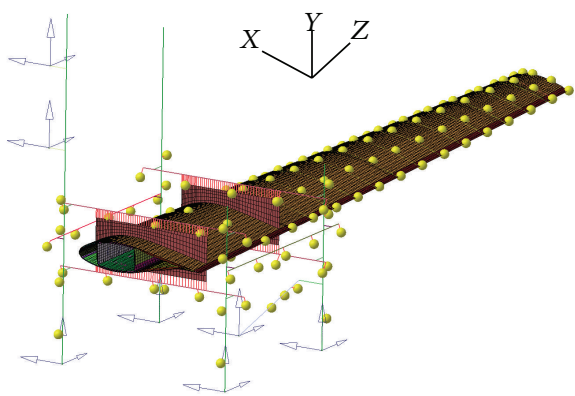

FIGURE 6: FE model of the blade section clamped to the support structure. Yellow bulbs denote test and FE geometry correlation node mapping. 


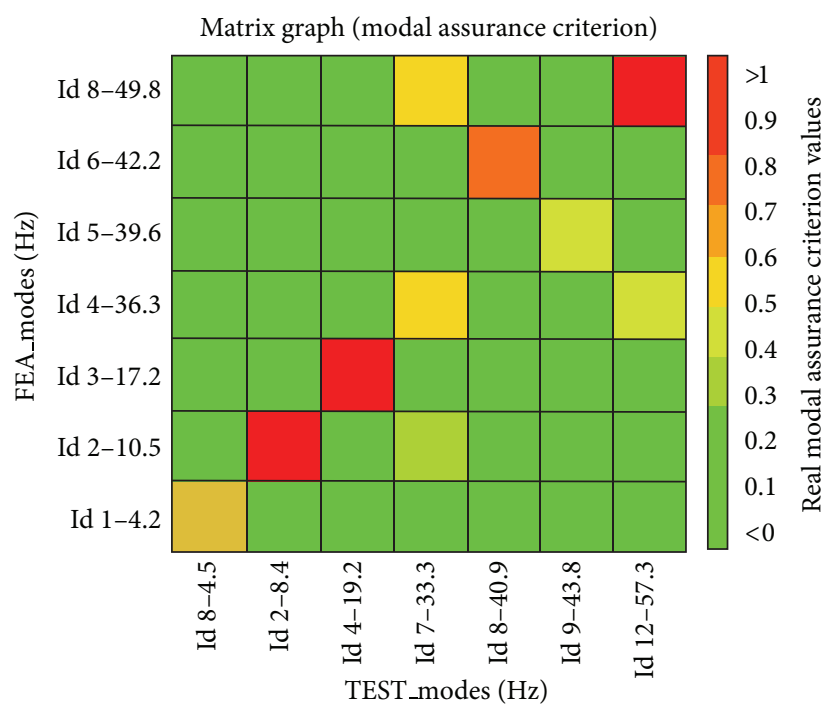

FIGURE 7: MAC matrix for test and FE simulation modal vectors of modified blade without support structure.

real structure interface between profile-cut plywood and the blade is realized on approximately $200 \mathrm{~mm}$ of width, while in the numerical model only single row of nodes is used.

3.3. Correlation Analysis for the Simulation and Test Results. Based on the estimated experimental modal model and modified blade FEM analysis models the correlation analysis can be applied. The FE model should yield natural frequencies values and mode shapes conforming to the measured. Modal assurance criterion is used as the original-modified blade simulation and also test-simulation correlation metrics.

The global coordinate system used to define the test model differs from that used for the FE model. In order to make the models match it is necessary to apply geometric correlation by translation and rotation of the test model (Figure 6). Next step is node mapping. The number of measurement nodes is much less than the FE nodes. Modal vectors are compared only for the nodes from $\mathrm{FE}$ which are located closest to the measurement points. Only the portion of the blade after the clamp is considered.

The blade section model was solved to compute mode shapes in the $0-60 \mathrm{~Hz}$ frequency bandwidth. Calculations were carried out at the CI TASK, Academic Computer Center in Gdańsk on a 50Tflop cluster. Modal assurance criterion was calculated for the corresponding modes in order to associate the closest numerical and experimental mode shapes The procedure accounted for both natural frequency value and the mode shape consistency (Table 2).

The following modes were investigated: 1st and 2nd flapwise bending, 1st and 2nd edgewise bending, and 1st torsional (Figure 4). The MAC matrix in Figure 7 clearly shows that the off-diagonal terms are low valued which confirms linear independence of estimated modal vectors. The best test and simulation modal vectors consistency can be observed for the 2nd flapwise mode (Table 2).

The consistency of the results can be recognized as satisfactory; however the present differences need to be further
TABLE 2: Initial consistency of the modal model parameters.

\begin{tabular}{lcccc}
\hline TEST & FE & \multicolumn{3}{c}{ Initial WT blade } \\
Freq. 1 & Freq. 2 & MAC value & $\begin{array}{c}\text { Freq. 2-Freq. } \\
1 \text { (Hz) }\end{array}$ & $\begin{array}{c}\text { Freq. 2-Freq. 1 } \\
\text { (\% of Freq. 1) }\end{array}$ \\
\hline 4.5 & 4.2 & 0.636 & -0.24 & -5.4 \\
8.4 & 10.5 & 0.94 & 2.1 & 24.9 \\
19.2 & 17.2 & 0.963 & -2.03 & -10.5 \\
33.3 & 36.3 & 0.503 & 3.02 & 9.1 \\
40.9 & 42.2 & 0.76 & 1.33 & 3.3 \\
43.8 & 39.6 & 0.479 & -4.2 & -9.6 \\
57.3 & 49.8 & 0.857 & -7.5 & -13.1 \\
\hline
\end{tabular}

investigated. Observing the values of the MAC criterion between test and simulation modes (Figure 7), differences can be notified. They are caused by the influence of the support structure and not perfectly excited 1st bending mode. Further investigation of observed differences is presented in Section 4.

\section{Updating of the Numerical Model to the Test Results}

Satisfactory conformity of the static tests and simulations results has proven the validity of the FE model of modified blade section. Structural dynamics analysis revealed the unsatisfactorily large difference in between tests and simulations. The main reason for these differences is associated to the influence of the flexibility of the support structure. It is complex structure constructed with numerous pipes clamping rings, screwed I beams, and plywood. Part of the structure is constrained to the next structure. For the improvement of the FE model the three-step routine was realized. In the first step sensitivity analysis of the model was 


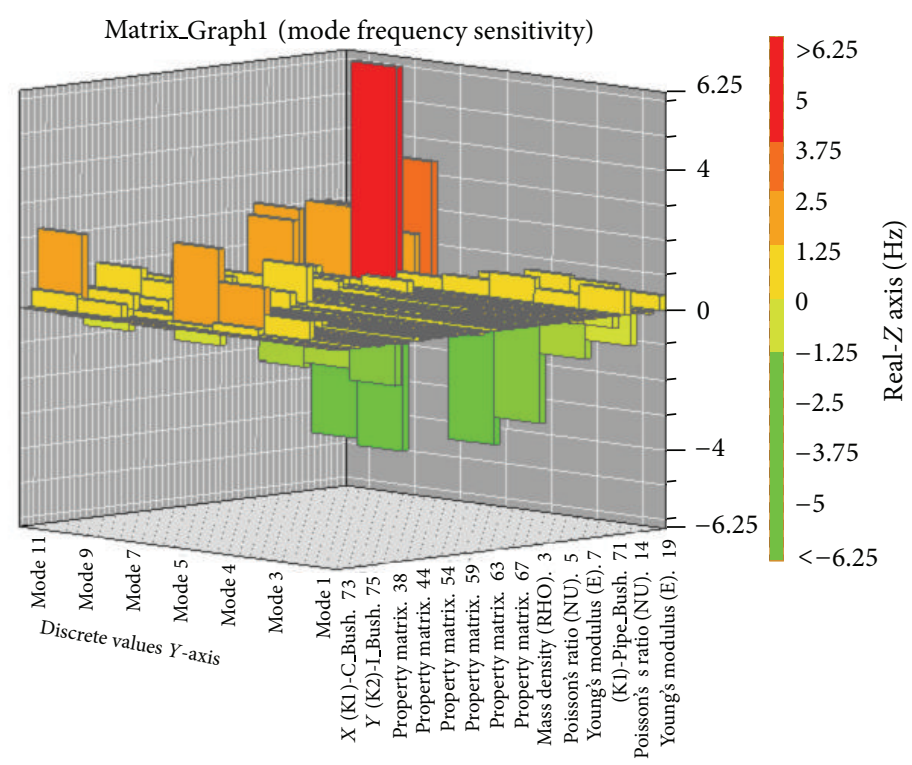

FIGURE 8: Frequency sensitivity matrix graphically presenting normalized magnitude of the impact of selected design variables (inputs) on the modes frequencies of interest (outputs).

computed in order to determine model parameters which are most influential on the investigated modes. In the second step the design of experiment (DOE) procedure to produce statistical data tabulating input-output relationships. In the third step the response surface model (RSM) is calculated to determine how model parameters influences on the natural frequencies. Study of responses obtained from particular values of the model parameters allows to update the FE model of support structure.

4.1. Sensitivity Analysis. Parameters of the original blade section model were assumed to be constant and were not a subject of updating analysis. 56 parameters characterizing the support structure and additional composite unidirectional layers model were defined as a design variable for the preliminary sensitivity analysis. They comprised material properties such as elasticity modulus, shear modulus and density of the additional composite unidirectional layers, plywood clamps, the rubber pads, the steel pipes, and the bushings. This study was realized to:

(i) identify parameters (inputs) which have no impact on the mode frequencies of interest (outputs);

(ii) identify inputs that cause significant change in the outputs.

Outcome of the frequency sensitivity analysis is presented in Figure 8. The total mass of the system was not known therefore the mass sensitivity was not computed. Based on the outcomes of the analysis the set of 7 parameters was selected as input variables for the design of experiment (Table 3).

Frequency sensitivity analysis provided information about most influential material properties of the supporting structure and additional composite layers. There are several uncertainties related to unknown properties of support structure construction components (Figure 9). C shape beams are
TABLE 3: Updated parameters as variables in the model and their initial values.

\begin{tabular}{lc}
\hline Name & Initial \\
\hline I Bush K1 & $2.96 E 7$ \\
Steel pipes E & $2.09 E 11$ \\
Steel E & $1.99 E 11$ \\
MAT9_7_G13 & $2.49 E 10$ \\
MAT9_7_G14 & $-1.57 E 10$ \\
MAT9_7_G24 & $-7.32 E 9$ \\
MAT9_7_G34 & $-6.85 E 9$ \\
MAT9_8_G56 & $-2.65 E 8$ \\
\hline
\end{tabular}

drilled; I shape clamp beams consist of two bolted C shape beams, plywood properties, and connections of components. Based on the frequency sensitivity analysis outcomes the material properties of the supporting structure and additional composite layers were selected to be updated parameters.

4.2. Design of Experiment. Computation of the FE model of the system under investigation takes large number of hours for a single run. Therefore applying optimization analysis which would require large number of runs is not a best available method of model updating. In the system with numerous variable inputs (factors) which affect the outputs (responses) the design of experiment procedure can be used to gather data. The result data is used to develop an approximate model (such as response surface method) linking outputs and inputs. Experimental design which was used is full factorial. It required computation of $2^{k}$ combinations where $k$ is a number of factors. With 7 factors (Table 3 ) applied number of runs was 128. It yielded 21 terms present in quadratic model. 


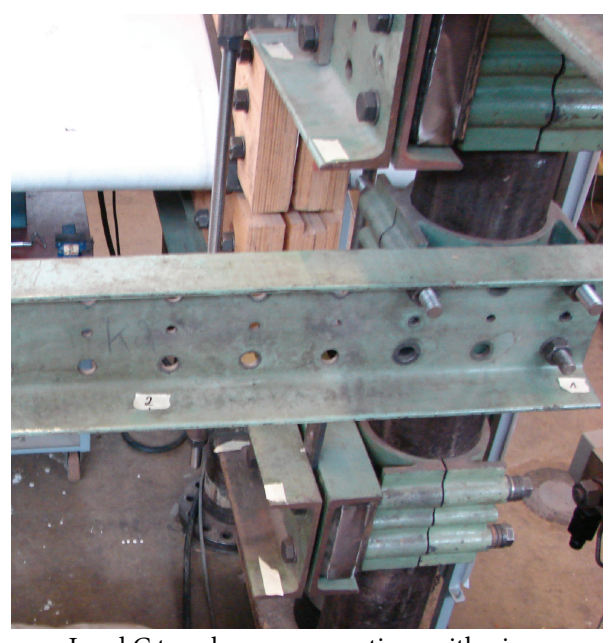

I and $\mathrm{C}$ type beams connections with pipes

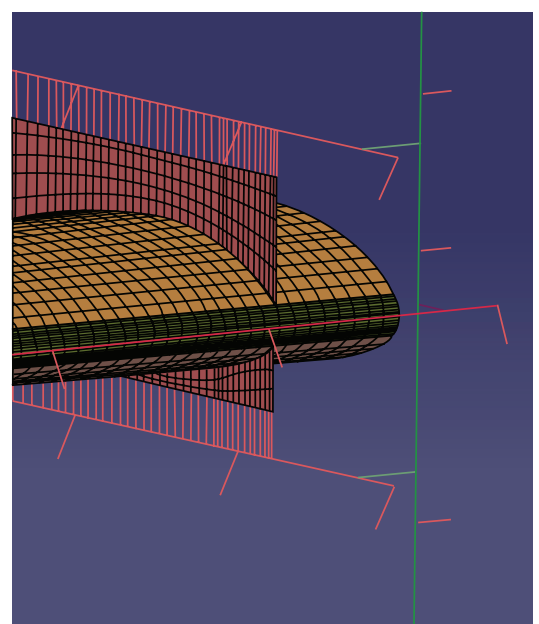

Connection model with bush type properties

FIGURE 9: Mountings of supporting structure modeled with steel pipes, steel, and bushing properties.

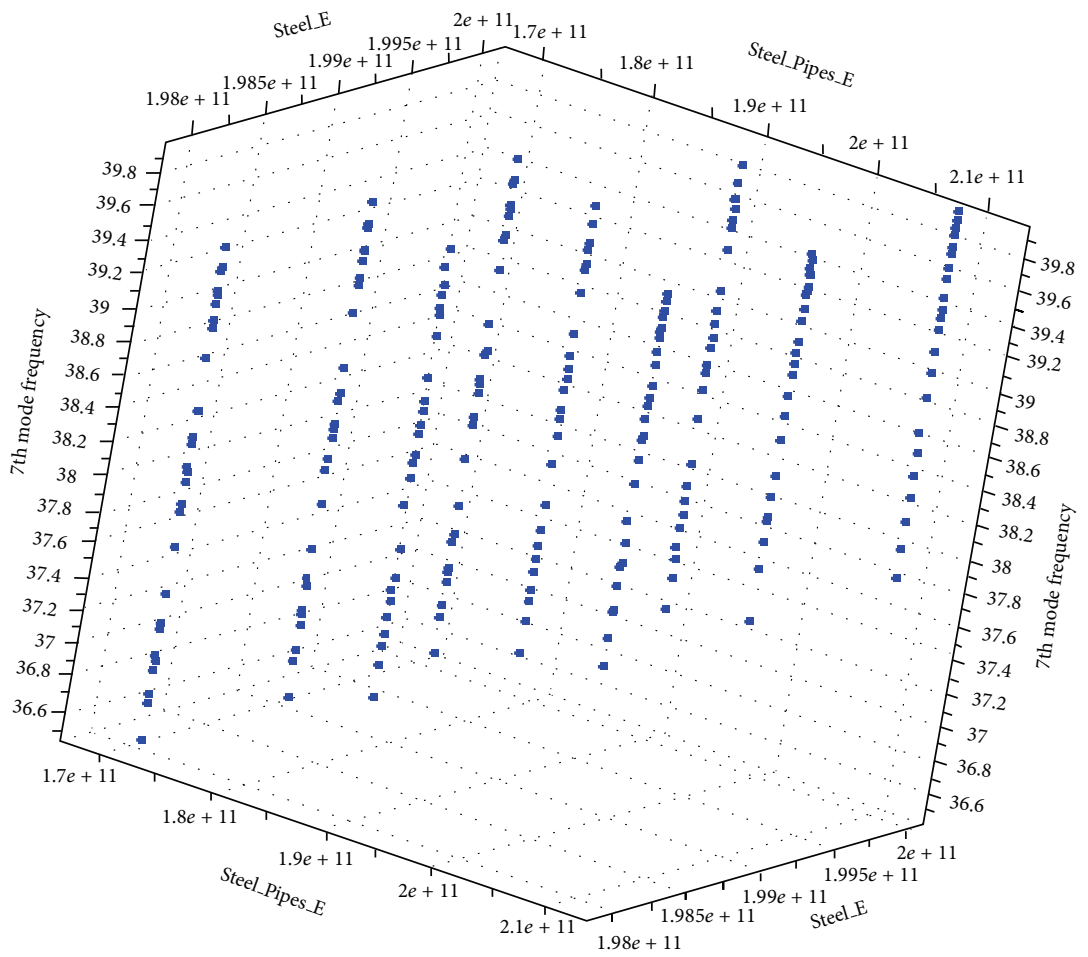

FIGURE 10: Example of 3D scatter plot of two inputs (factors) impact on the output (response) 7th mode frequency.

Analysis of DOE data was performed to identify inputs (factors) which introduce significant change in output (response). For this purpose numerous scatter plots were drawn and analyzed. Example of 3D scatter plot is shown in Figure 10. It also allows to screen for response values computed from model which are closest to the values obtained from measurement. The DOE scatter plot shows the output (response) values for each level of each input (factor) variable. It can be observed that the location and scale vary for both within a factor variable (nominal, minimum, and maximum) and between different factor variables (Young modulus of steel pipes and Young modulus of steel bars). Review of the scatter plots for number of variables allows to identify important factors (inputs) and provides a ranked list of important factors from a results of design of experiment.

Next to the scatter plot the histogram plots were drawn to present the distribution of the computed responses. It is possible to identify the center, spread, and outliers. Example of the histogram plot for the 9th mode frequency is presented in Figure 11. Vertical axis shows number of runs corresponding to the response on horizontal axis. 


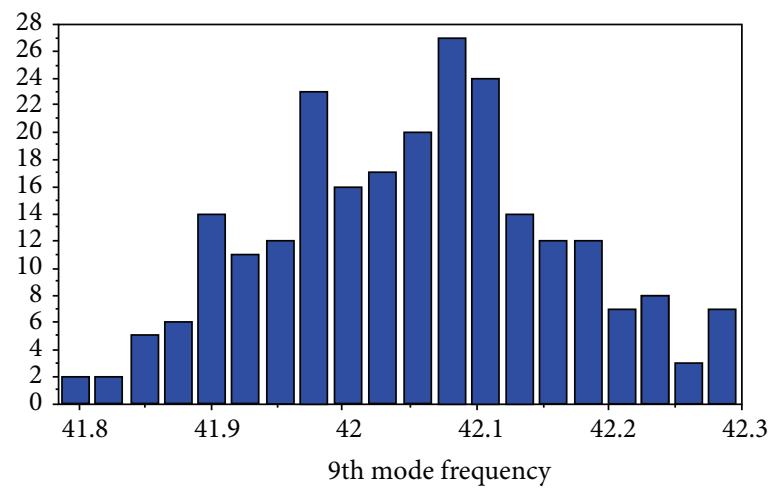

FIGURE 11: Histogram plot of 9th mode frequency distribution.

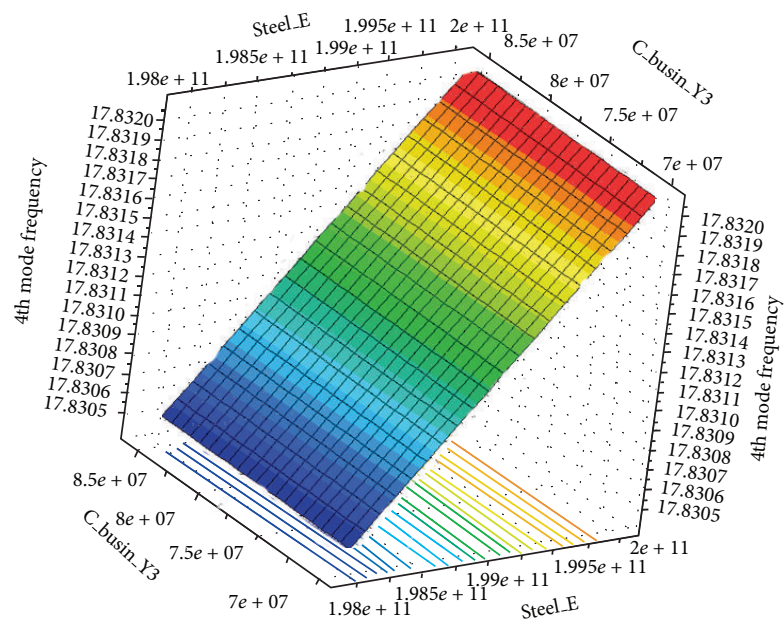

(a)

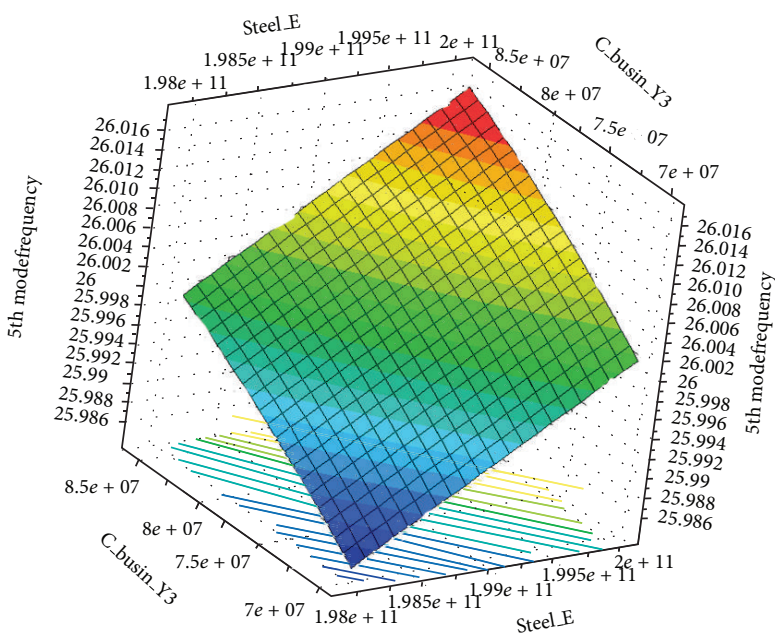

(b)

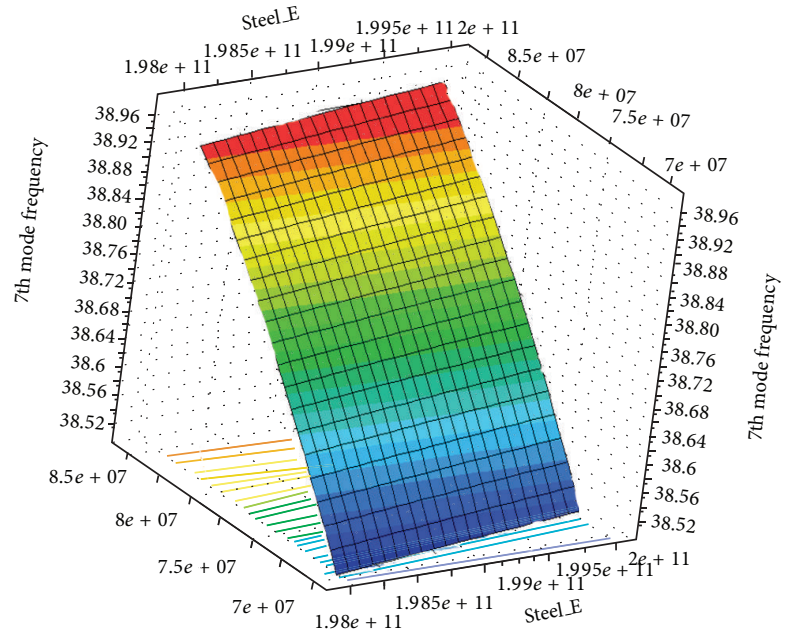

(c)

FIGURE 12: Quadratic response surface models 3D perspective plot for the same input variables and (a) 4th mode, (b) 5th mode, and (c) 7th mode frequency. 


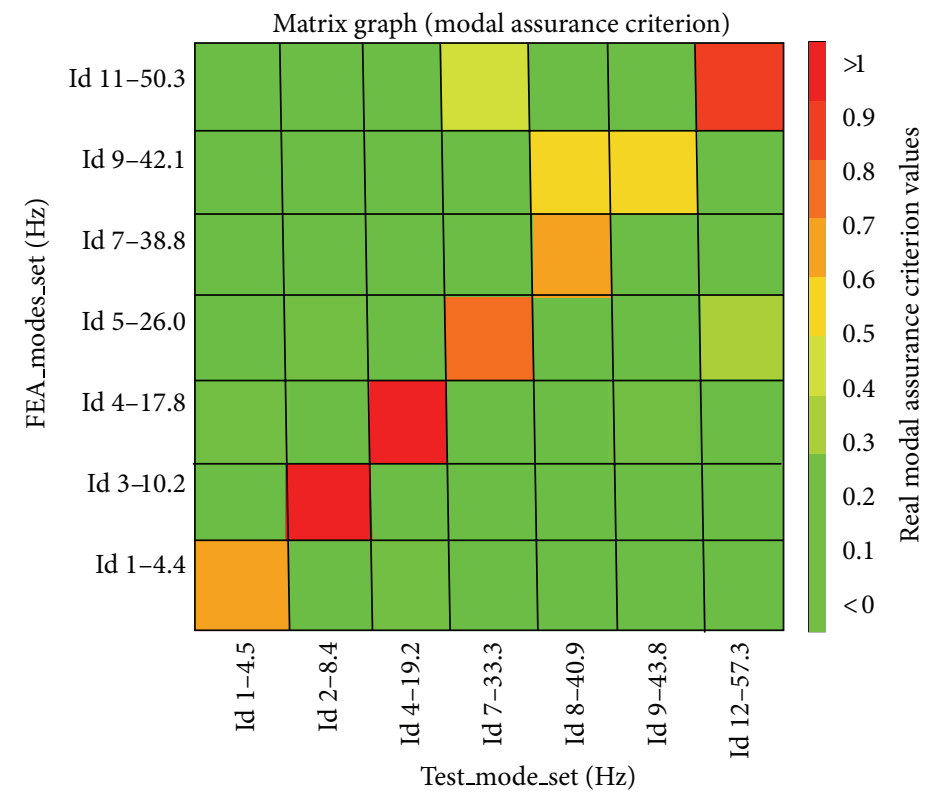

FIGURE 13: MAC matrix, test versus updated FE model of the blade with flexible support.

TABLE 4: Updated parameters and their final values.

\begin{tabular}{lc}
\hline Name & Final \\
\hline I Bush K1 & $3.289 E 7$ \\
Steel pipes E & $1.9 E 11$ \\
Steel E & $2.0 E 11$ \\
MAT9_7_G13 & $1.122 E 10$ \\
MAT9_7_G14 & $-1.424 E 10$ \\
MAT9_7_G24 & $-6.644 E 9$ \\
MAT9_7_G34 & $-6.225 E 9$ \\
MAT9_8_G56 & $-2.413 E 8$ \\
\hline
\end{tabular}

Histogram of 9th mode frequency shows the results distribution is almost symmetric with most of the results located in the proximity of nominal value. Data is not skewed nor contains outliers and the distribution is moderate tailedthe number of runs is dying off out in the tails of the histogram.

4.3. Response Surface Model. Based on design of experiment, response surface method was computed using polynomial model of several factors, including terms for quadratic crossproducts displayed in Figure 12.

The RSM methodology allows for further processing of the DOE results. 3D graphs are plotted based on the available design variables contributions. The inherent trend of the factor-response multidimensional relationship was computed for selected inputs applying Taylor polynomial. Statistical model allows to approximate data and correctly predicts the response without lengthy and costly simulation runs.

Based on the analysis of the RSM model the values of the FE model parameters (factors/inputs) were selected (Table 4).
As a result a correlation analysis of updated and validated FE model shows significant improvement in comparison to the results from original FE model (Figure 13). Test modes of $40.9(\mathrm{~Hz})$ and $43.8(\mathrm{~Hz})$ correspond better with the FE modes.

Comparison of frequency value differences of initial (Table 2) and final models (Table 5) shows that the highest discrepancy between simulation and experimental frequencies could be observed for torsional mode for both initial and final model. Frequency difference between FE initial and final model for Test modes $4.5(\mathrm{~Hz})$ has decreased from $-5.4 \%$ to $-2.2 \%$ and for $19.2(\mathrm{~Hz})$ mode from $-10.5 \%$ to $-7.3 \%$.

\section{Conclusions}

This paper presents some results and aspects of the multidisciplinary and interdisciplinary research oriented for the numerical study in updating of the finite element model of a wind turbine blade section using experimental modal analysis results.

Experimental test data examples were shown and used for two purposes: firstly to evaluate the influence of the flexible support structure onto measurement results of the bend-twist coupled blade section and secondly to use the test results for FE models updating. The common observation from displayed investigations is that the blade section model accuracy strongly depends on the boundary conditions represented in the model. Simple approaches based on constraining degrees of freedom led to discrepancies in between experimental and numerical results. Presented research introduced complex parametric model of the flexible support structure which led to more realistic structural behavior of the objectsupport system. In detail the plywood plates and steel profiles were included and contact elements were applied to model the contact between the clamps and the blade section. As expected that the more sophisticated support structure FE 
TABLE 5: Final consistency of the modal model parameters.

Final WT blade (versus initial)

\begin{tabular}{lcccc}
$\begin{array}{l}\text { TEST } \\
\text { Freq. 1 }\end{array}$ & FE & MAC value & $\begin{array}{c}\text { Freq. 2-Freq. } \\
1(\mathrm{~Hz})\end{array}$ & $\begin{array}{c}\text { Freq. 2-Freq. 1 } \\
\text { (\% of Freq. 1) }\end{array}$ \\
\hline 4.5 & Freq. 2 & $0.634(0.636)$ & $-0.1(-0.24)$ & $-2.2(-5.4)$ \\
8.4 & 4.4 & $0.942(0.94)$ & $1.73(2.1)$ & $20.6(24.9)$ \\
19.2 & 10.2 & $0.962(0.963)$ & $-1.41(-2.03)$ & $-7.3(-10.5)$ \\
33.3 & 17.8 & $0.722(0.503)$ & $-7.3(3.02)$ & $-21.9(9.1)$ \\
40.9 & 26 & $0.602(0.76)$ & $-2.11(1.33)$ & $-5.2(3.3)$ \\
43.8 & 38.8 & $0.538(0.479)$ & $-1.72(-4.2)$ & $-3.9(-9.6)$ \\
57.3 & 42.1 & $0.802(0.857)$ & $-7.03(-7.5)$ & $-12.3(-13.1)$ \\
\hline
\end{tabular}

representation has improved the consistency in between test and simulations. Design of experiment with response surface model study allowed successful updating of the FE model confirmed by modal assurance criterion. The comparison of experimental and numerical models clearly shows the influence of support structure flexibility.

\section{Conflict of Interests}

The authors declare that there is no conflict of interests regarding the publication of this paper.

\section{Acknowledgments}

Vestas Wind Systems A/S has provided and modified the blade sections presented in this study. The work is partly supported by the Danish Energy Authority through the 2007 Energy Research Programme (EFP 2007). The supported EFP-Project is titled "Anisotropic beam model for analysis and design of passive controlled wind turbine blades" and has journal no. 33033-0075. The support is gratefully acknowledged and highly appreciated. Authors would like to acknowledge the assistance of Mr. Philipp Haselbach. Research presented in Section 5 was conducted in the context of the FP7 project STA-DY-WI-CO Ref. no. 251309, IMESCON Ref. no. 264672, and MARE-WINT Ref. no. 309395. Computations were performed on a 50Tflop cluster in TASK Academic Computer Centre in Gdansk, Poland. This research was supported in part by PL-Grid Infrastructure.

\section{References}

[1] C. Ong and S. W. Tsai, Design, Manufacture and Testing of a Bend-Twist D-spar, Sandia National Laboratories, SAND, 1999.

[2] D. W. Lobitz, P. S. Veers, and G. R. Eisler, "The use of twistedcoupled blades to enhance the performance of horizontal axis wind turbines," Sandia National Laboratories SAND01-1303, Sandia National Laboratories, 2001.

[3] J. Locke and I. C. Hildago, The Implementation of Braided Composite Materials in the Design of a Bend-Twist Coupled Blade, Sandia National Laboratories, SAND02-2425, Sandia National Laboratories, 2002.
[4] J. M. Walsh, Composite Material Bend-Twist Coupling for Wind Turbine Blade Applications, AAT 1470715, University of Wyoming, Laramie, Wyo, USA, 2009.

[5] T. Kim, A. M. Hansen, and K. Branner, "Development of an anisotropic beam finite element for composite wind turbine blades in multibody system," Renewable Energy, vol. 59, pp. 172183, 2013.

[6] P. Berring, K. Branner, C. Berggreen, and H. W. Knudsen, "Torsional performance of wind turbine blades-part I: experimental investigation," in Proceedings of the 16th International Conference of Composite Materials, Kyoto, Japan, July 2007.

[7] K. Branner, P. Berring, C. Berggreen, and H. W. Knudsen, “Torsional performance of wind turbine blades-part II: numerical verification," in Proceedings of the 16th International Conference of Composite Materials, Kyoto, Japan, July 2007.

[8] M. Luczak, S. Manzato, B. Peeters, K. Branner, P. Berring, and M. Kahsin, "Dynamic investigation of twist-bend coupling in a wind turbine blade," Journal of Theoretical and Applied Mechanics, vol. 49, no. 3, pp. 765-789, 2011.

[9] T. Marwala, Finite-Element-Model Updating Using Computational Intelligence Techniques: Applications to Structural Dynamics, Springer, New York, NY, USA, 2010.

[10] M. Friswell and J. E. Mottershead, Finite Element Model Updating in Structural Dynamics, Springer, New York, NY, USA, 1995.

[11] M. Link, "Updating of analytical models-review of numerical procedures and application aspects," in Proceedings of the Structural Dynamics Forum SD2000, 1999.

[12] S. Manzato, B. Peeters, and A. Toso, Linking Models and Experiments, vol. 2, Springer, 2011.

[13] C. Soize, "Stochastic modeling of uncertainties in computational structural dynamics-recent theoretical advances," Journal of Sound and Vibration, vol. 332, no. 10, pp. 2379-2395, 2013.

[14] A. Berman and E. J. Nagy, "Improvement of a large analytical model using test data," AIAA journal, vol. 21, no. 8, pp. 1168$1173,1983$.

[15] M. Sanayei, G. R. Imbaro, J. A. S. McClain, and L. C. Brown, "Structural model updating using experimental static measurements," Journal of Structural Engineering, vol. 123, no. 6, pp. 792798, 1997.

[16] B. Jaishi and W. Ren, "Finite element model updating based on eigenvalue and strain energy residuals using multiobjective optimisation technique," Mechanical Systems and Signal Processing, vol. 21, no. 5, pp. 2295-2317, 2007.

[17] D. Foti, M. Diaferio, N. I. Giannoccaro, and M. Mongelli, "Ambient vibration testing, dynamic identification and model 
updating of a historic tower," NDT \& E International, vol. 47, pp. 88-95, 2012.

[18] D. Ribeiro, R. Calçada, R. Delgado, M. Brehm, and V. Zabel, "Finite element model updating of a bowstring-arch railway bridge based on experimental modal parameters," Engineering Structures, vol. 40, pp. 413-435, 2012.

[19] R. H. Myers, D. C. Montgomery, and C. M. Anderson-Cook, Response Surface Methodology: Process and Product Optimization Using Designed Experiments, Wiley Series in Probability and Statistics, Wiley, Hoboken, NJ, USA, 3rd edition, 2009.

[20] B. Goller, M. Broggi, A. Calvi, and G. I. Schuëller, "A stochastic model updating technique for complex aerospace structures," Finite Elements in Analysis and Design, vol. 47, no. 7, pp. 739752, 2011.

[21] İ. Batmaz and S. Tunali, "Small response surface designs for metamodel estimation," European Journal of Operational Research, vol. 145, no. 2, pp. 455-470, 2003.

[22] V. J. Romero, L. P. Swiler, and A. A. Giunta, "Construction of response surfaces based on progressive-lattice-sampling experimental designs with application to uncertainty propagation," Structural Safety, vol. 26, no. 2, pp. 201-219, 2004.

[23] S. Chakraborty and A. Sen, "Adaptive response surface based efficient finite element model updating," Finite Elements in Analysis and Design, vol. 80, pp. 33-40, 2014.

[24] W. Ren and H. Chen, "Finite element model updating in structural dynamics by using the response surface method," Engineering Structures, vol. 32, no. 8, pp. 2455-2465, 2010.

[25] M. Luczak, K. Dziedziech, and M. Vivolo, "Contact versus noncontact measurement of a helicopter main rotor composite blade," in Proceedings of the 9th International Conference on Vibration Measurements by Laser and Noncontact Techniques (AIVELA '10), vol. 1253 of AIP Conference Proceedings, p. 352, Ancona, Italy, June 2010.

[26] B. Peeters, H. Van Der Auweraer, P. Guillaume, and J. Leuridan, "The PolyMAX frequency-domain method: a new standard for modal parameter estimation?" Shock and Vibration, vol. 11, no. 3-4, pp. 395-409, 2004.

[27] D. J. Ewins, Modal Testing: Theory, Practice, and Application, Research Studies Press, Baldock, UK, 2000.

[28] V. A. Fedorov, N. Dimitrov, C. Berggreen, S. Krenk, K. Branner, and P. Berring, "Investigation of structural behaviour due to bend-twist couplings in wind turbine blades," in Proceedings of the NAFEMS Nordic Seminar of Simulating Composite Materials and Structures, NAFEMS, Esbjerg, Denmark, 2010. 

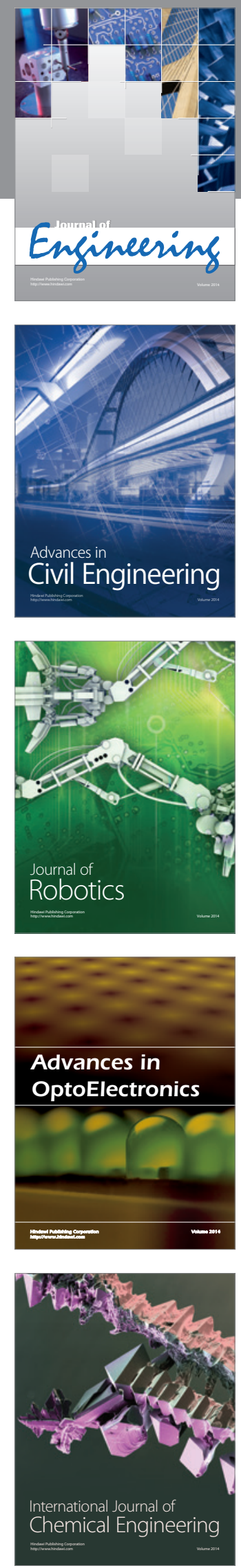

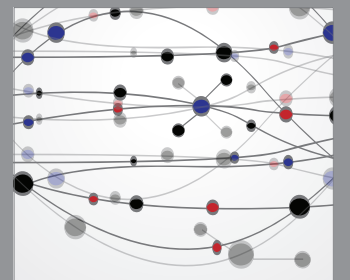

The Scientific World Journal
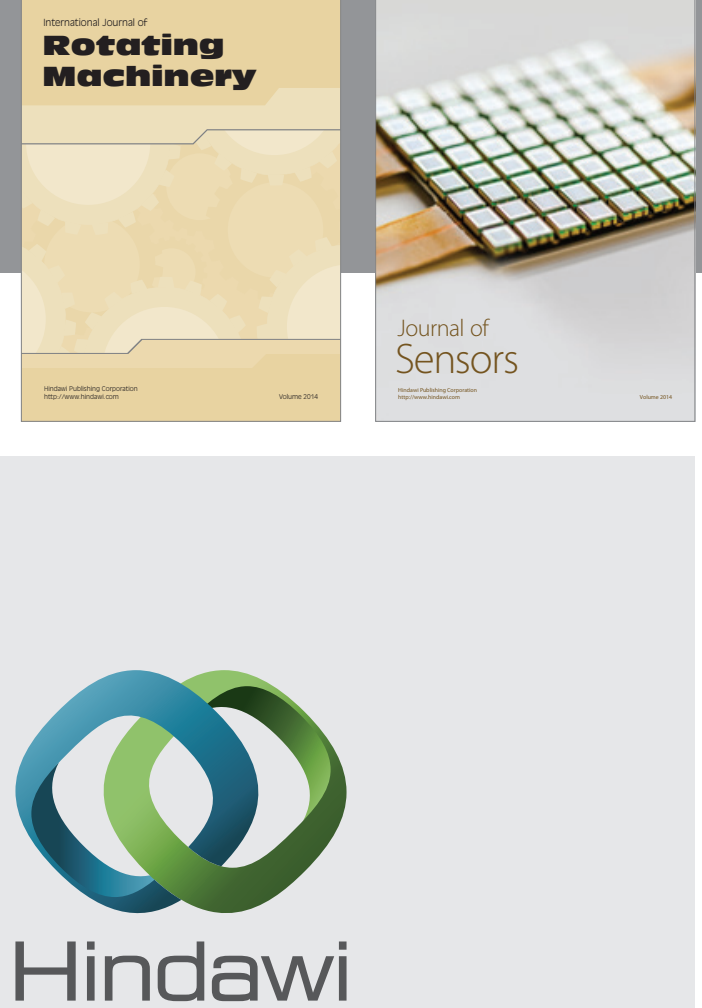

Submit your manuscripts at http://www.hindawi.com
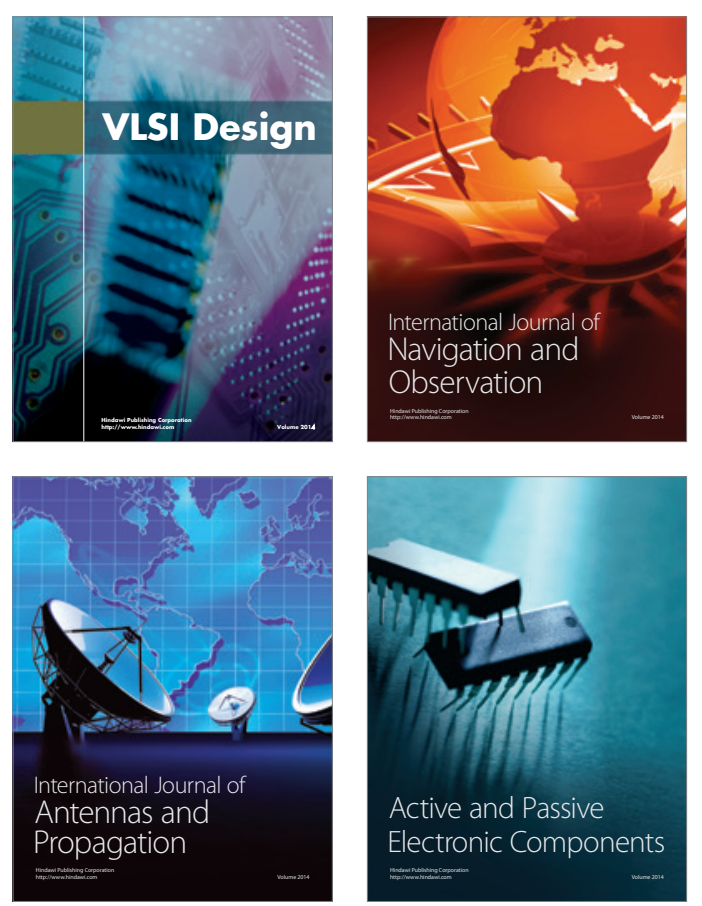
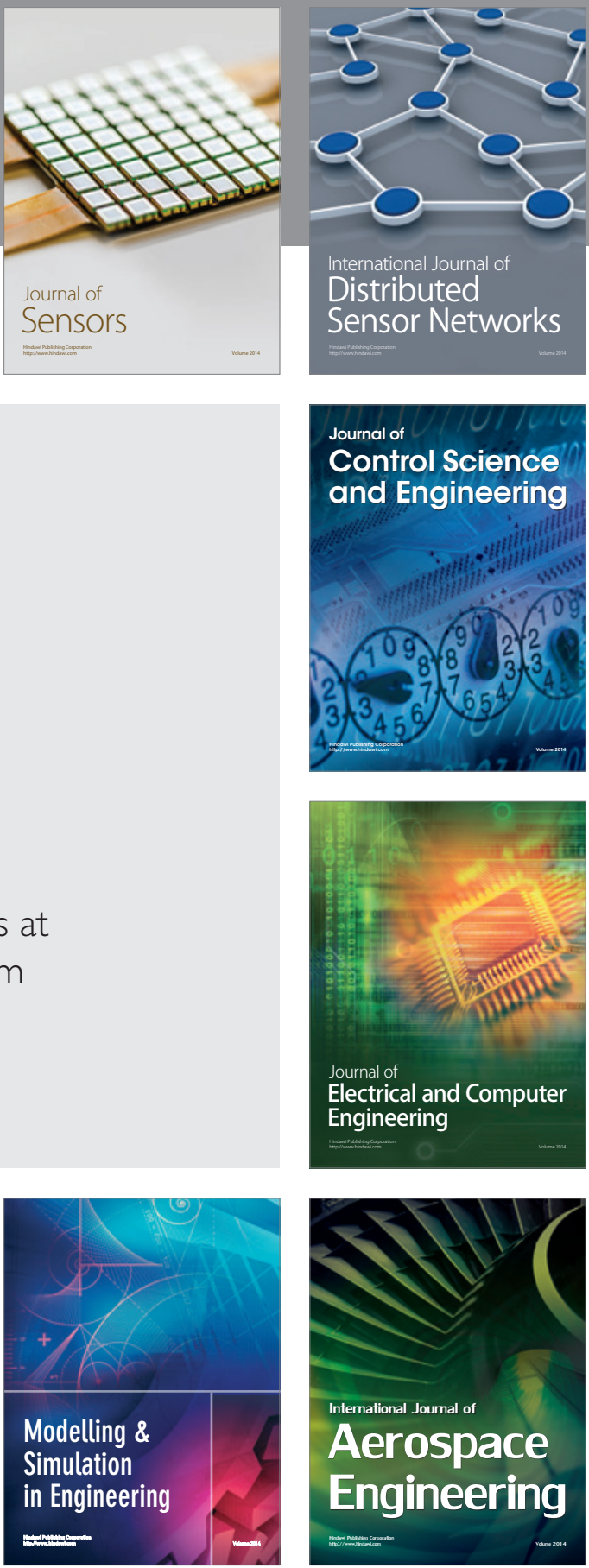

Journal of

Control Science

and Engineering
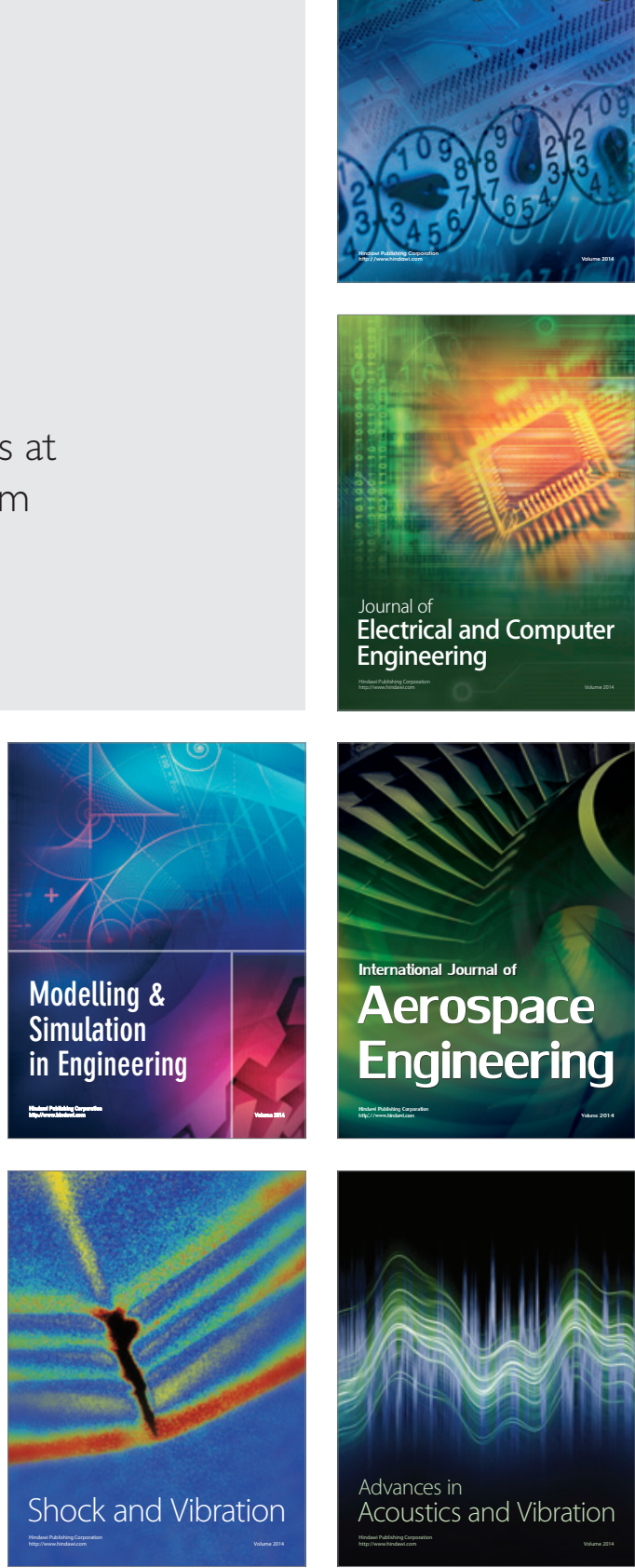